\title{
DESENVOLVIMENTO DE PRÁTICAS EDUCACIONAIS INCLUSIVAS E O TRABALHO COM PROJETOS
}

Ana Virginia Isiano Lima, Klaus Schlünzen Junior, Danielle Aparecida do Nascimento dos Santos, Ana Mayra Samuel da Silva.

Universidade Estadual Paulista - UNESP, Programa de Pós-Graduação em Educação (PPGE), Presidente Prudente, SP. E-mail: anaisianolima@gmail.com. Órgão de fomento: Coordenação de Aperfeiçoamento de Pessoal de Nível Superior (CAPES).

\section{RESUMO}

Ao considerarmos a constituição de escolas inclusivas como um dos desafios inerentes ao cenário educacional brasileiro, devemos atuar na construção de práticas de ensino e aprendizagem que garantam o reconhecimento das diferenças dos estudantes. O estudo desenvolvido no Mestrado em Educação da Universidade Estadual Paulista (UNESP), campus de Presidente Prudente, buscou analisar os reflexos do trabalho com projetos, em termos das estratégias de ensino e aprendizagem em uma escola pública inserida em uma comunidade de risco. Por meio de uma abordagem qualitativa foi realizado um diagnóstico do contexto escolar e intervenções na sala de aula. Durante a intervenção os estudantes e a professora escolheram um tema por intermédio do qual foram vivenciadas situações de aprendizagem que promoveram a conscientização e a construção do conhecimento. A análise dos dados permite constatar que as práticas relacionadas ao contexto favoreceram a construção da consciência sobre a sua realidade e a construção do conhecimento.

PALAVRAS-CHAVE: Educação Inclusiva, Trabalho com Projetos, Práticas Inclusivas, Ensino e Aprendizagem, Contexto.

\section{DEVELOPMENT OF INCLUSIVE EDUCATIONAL PRACTICES AND WORK WITH PROJECTS}

\begin{abstract}
Considering the constitution of inclusive schools as one of the challenges inherent in the Brazilian educational scenario, we must act in the construction of teaching and learning practices that guarantee the recognition of students' differences. The study developed in the Masters of Education of the São Paulo State University (UNESP), Campus of Presidente Prudente, sought to analyze the reflexes of work with projects, in terms of teaching and learning strategies in a public school inserted in a community at risk. Through a qualitative approach, a diagnosis of the school context and interventions in the classroom was carried out. During the intervention the students and the teacher chose a theme through which they experienced experiences of learning that promoted the awareness and the construction of knowledge. The analysis of the data allows to verify that the practices related to the context favored the construction of the consciousness about its reality and the construction of the knowledge.
\end{abstract}

KEYWORDS: Inclusive Education, Work with Projects, Inclusive Practices, Teaching and Learning, Context. 


\section{INTRODUÇÃO}

A constituição da Educação Inclusiva pressupõe o acolhimento de todos os estudantes no espaço escolar, bem como, o desenvolvimento de práticas pedagógicas que promovam situações de ensino e aprendizagem significativas. Mantoan (2008) enfatiza que a inclusão implica em mudanças no paradigma educacional, promovendo, assim, a exclusão de práticas homogeneizadoras que negam as diferenças e que prejudicam a trajetória educacional dos estudantes.

O reconhecimento da Educação Inclusiva, enquanto diretriz educacional prioritária, se intensifica a partir da década de 1990, com o reconhecimento de que as instituições de ensino que atuam com base nessa perspectiva se configuram como os meios mais capazes de combater atitudes discriminatórias, valorizando e reconhecendo as diferenças individuais de cada estudante.

Diante disso, o cerne deste artigo são os resultados obtidos na pesquisa de Mestrado intitulada "Trabalho com projetos na perspectiva da Educação Inclusiva com estudantes em uma comunidade de risco", desenvolvida no âmbito do Programa de Pós-Graduação em Educação (PPGE), da Universidade Estadual Paulista "Júlio de Mesquita Filho" (UNESP), campus de Presidente Prudente. Entre outros aspectos, a pesquisa buscou o estabelecimento de novas práticas pedagógicas em uma sala com estudantes em situação de risco e problemas de aprendizagem. Usando a pedagogia de projetos, houve a promoção de um processo de aprendizagem mais dinâmico, significativo e interessante para os estudantes.

A pesquisa foi desenvolvida em uma Escola Municipal do município de Presidente Prudente/SP, localizada em um bairro periférico e de rearranjo social, com problemas socioeconômicos. Por apresentar resultados insatisfatórios no Índice de Desenvolvimento da Educação Básica (IDEB) a instituição foi considerada pela Secretaria Municipal de Educação de Presidente Prudente um contexto em que intervenções em termos de alfabetização, letramento e inclusão deveriam ser propostas em parceria com projetos e universidades do município.

Desse modo, a demanda pela efetivação de parcerias que resultassem no desenvolvimento e na aprendizagem dos estudantes permitiu que a pesquisa fosse direcionada a partir da utilização de práticas de ensino e aprendizagem que tinham como princípios a valorização do contexto, das especificidades e das diferenças que norteavam a sala de aula do 5 o ano $B$, local em que o estudo foi realizado. Nessa perspectiva, o trabalho com projetos se configurou como uma possibilidade para a reelaboração das práticas educativas a partir da valorização dos interesses dos educandos.

Conforme Almeida (2011), o desenvolvimento do trabalho com projetos em sala de aula permite o rompimento com a limitação das atividades relacionadas ao saber disciplinar, permitindo, assim, a criação de novas situações de ensino e aprendizagem, que se aproximem da realidade e do contexto dos estudantes. Além disso, as ações desenvolvidas no projeto permitem a mobilização de "saberes específicos para enfrentar situações reais por meio do desenvolvimento de competências e habilidades fundamentais para a autonomia em relação à própria vida e ao trabalho" (ALMEIDA, 2011, p. 57).

Nessa perspectiva, o trabalho com projetos aproxima a escola ao contexto em que os estudantes estão inseridos, proporcionando condições para que, a partir da interdisciplinaridade, os conteúdos escolares se aproximem da vida dos educandos por meio de temas específicos. Araújo (2014) enfatiza que, além de trabalhar os conhecimentos científicos e culturais tradicionais, as instituições de ensino devem desenvolver práticas que valorizem os conhecimentos que surgem do contexto dos estudantes. "Os temas cotidianos e os saberes populares são o ponto de partida, e muitas vezes também de chegada, para as aprendizagens escolares [...]" (ARAÚJO, 2014, p. 70).

Nessa perspectiva, o artigo é centrado na análise sobre os reflexos do desenvolvimento do trabalho com projetos, em termos das estratégias de ensino do docente e da aprendizagem dos estudantes, bem como a construção da consciência sobre a temática vivenciada. 


\section{METODOLOGIA}

A abordagem metodológica da pesquisa é qualitativa, pois conforme Lüdke e André (1995, p.13) a abordagem qualitativa "[...] envolve a obtenção de dados descritivos, obtidos no contato direto do pesquisador com a situação estudada, enfatiza mais o processo do que o produto e se preocupa em retratar a perspectiva dos participantes [...]". Bogdan e Biklen (1994) definem que a investigação qualitativa possui cinco características, que se expressam em grande parte dos estudos desenvolvidos com base nessa abordagem. Diante disso, a pesquisa realizada é caracterizada como qualitativa por apresentar características definidas pelos autores, que são:

1. Na investigação qualitativa a fonte direta de dados é o ambiente natural, constituindo o investigador o instrumento principal [...].

2. A investigação qualitativa é descritiva [...].

3. Os investigadores qualitativos interessam-se mais pelo processo do que simplesmente pelos resultados ou produtos [...].

4. Os investigadores qualitativos tendem a analisar os seus dados de forma indutiva [...].

5. O significado é de importância vital na abordagem qualitativa [...]. (BOGDAN e BIKLEN, 1994, p. 47-50).

De modo a articular a pesquisa desenvolvida com as características apresentadas pelos autores, é possível perceber que a investigação qualitativa permitiu a aproximação ao contexto em que os estudantes estavam inseridos. Diante da inscrição no Comitê de Ética em Pesquisa (CEP), sendo o número do Certificado de Apresentação para Apreciação Ética (CAAE): 10206912.2.0000.5402, o trabalho de campo foi realizado na escola no período de maio a dezembro de 2015, em encontros de duas a três vezes por semana. Inicialmente, realizamos um diagnóstico do espaço escolar, a partir do desenvolvimento de entrevistas sistemáticas, objetivando compreender os desafios e conflitos inerentes ao contexto que se articulavam com as necessidades dos estudantes do 50 ano B.

Diante dessas ações, verificamos, juntamente com os estudantes e a professora, o contexto em que estavam inseridos para que pudéssemos definir o tema do projeto desenvolvido. Os dados coletados durante as observações e intervenções, realizadas nesta etapa, foram registrados no diário de campo e capturados em fotografias, para ilustrar de forma minuciosa as ações que ocorreram, evidenciando, assim, a característica descritiva da abordagem qualitativa.

A construção, desenvolvimento e avaliação do projeto se aproximam das características definidas pelos autores no sentido de que as intervenções realizadas priorizavam o processo, a participação e envolvimento dos estudantes e professora e a sua percepção enquanto sujeitos ativos na construção do novo conhecimento. Outro aspecto a se considerar é que os dados foram analisados com o intuito de contribuir com o contexto pesquisado, indicando novas possibilidades de se ensinar e aprender a partir da valorização das especificidades de cada estudante e de sua realidade.

\section{RESULTADOS}

Para iniciarmos o trabalho com projetos na sala de aula, consideramos os preceitos de Hernández e Ventura (1998) e Araújo (2014), que enfatizam que o ponto de partida para o desenvolvimento de projetos é a escolha do tema, que tenta responder aos questionamentos dos estudantes e busca relacionar os conteúdos científicos e culturais ao contexto em que estão inseridos. Diante disso, a primeira estratégia realizada foi questionar os estudantes do 50 ano $\mathrm{B}$ sobre qual temática seria desenvolvida durante o projeto. 
Considerando o contexto social em que estavam inseridos, realizamos questionamentos que pudessem mobilizar a reflexão sobre qual tema era necessário e relevante para ser pesquisado e estudado naquele momento. Após realizarmos os questionamentos, que envolviam: "Qual tema pode ser escolhido para compreendermos o nosso bairro?" "Como podemos atuar na transformação da nossa realidade?" "O que podemos fazer para sermos percebidos na escola $e$ para mobilizar outros estudantes?", os estudantes decidiram que o tema Drogas seria o mais relevante para ser estudado naquele momento.

Dialogamos com os estudantes para definirmos qual questionamento nortearia o desenvolvimento das ações que seriam realizadas no projeto. Hernández e Ventura (1998) apontam a necessidade de se estabelecer uma série de hipóteses sobre o que se espera saber, bem como, as perguntas que devem ser respondidas. Assim, os estudantes definiram que iam compreender as concepções que envolviam a prevenção do uso de drogas, para que, assim, pudessem refletir sobre o contexto social em que estavam inseridos. Dessa forma, o problema a ser resolvido pelos estudantes foi: Como podemos atuar na prevenção do uso de drogas em nossa escola e em nossa comunidade?

As intervenções realizadas na sala de aula iniciaram-se a partir da identificação dos aspectos que seriam trabalhados no projeto. Diante disso, os estudantes iniciaram uma tarefa de busca de informações que contemplavam e ampliavam a temática do projeto. Ao lermos e refletirmos juntos sobre os textos, verificamos que os estudantes buscavam participar das discussões, cada um de sua maneira, destacando sempre exemplos percebidos em seu contexto social. Durante o debate sobre os tipos de drogas existentes, um dos estudantes apontou: "meu pai fuma bastante, eu jogo os cigarros no lixo escondido", nessa mesma concepção, outro estudante disse: "meu pai bebia, mas agora parou porque ele vem aqui na escola agora". Assim, Freire (2013) acrescenta que os estudantes expressam níveis de percepções sobre a sua realidade a partir da visão de mundo que possuem e das relações que estabelecem com o tema.

Após o processo de busca, solicitamos que os estudantes realizassem o tratamento das novas informações, como preconizam Hernández e Ventura (1998). Para isso, os estudantes sugeriram que cada um escolhesse uma maneira de expressar o entendimento em relação às informações coletadas. Considerando os preceitos de Mantoan (2008) e Schlünzen (2015), que enfatizam que o sucesso da aprendizagem é relacionado a exploração dos talentos e habilidades de cada um, permitimos que cada estudante escolhesse a maneira de se expressar. Ao propormos a atividade, cada estudante apresentou um nível de compreensão. Alguns expressaram o entendimento a partir de desenhos, textos curtos, frases e criação de paródia.

Considerando as concepções dos estudantes em relação à temática vivenciada, as atividades seguintes envolviam a busca de informações, realizada inicialmente e, perpassavam por uma pesquisa de campo, realizada na sala do 40 ano A. Schlünzen e Santos (2016) apontam que o processo de ensino e aprendizagem desenvolvido durante o trabalho com projetos transforma os estudantes em seres atuantes, que têm a oportunidade de descobrirem suas competências e habilidades, fatos esses, que foram vivenciados durante esta pesquisa.

Após a coleta de dados, as respostas foram verificadas e, a partir disso, envolvemos textos que apresentavam gráficos e tabelas, para que, assim, os estudantes tivessem acesso a diferentes maneiras de tratar as informações coletadas. Para que os dados fossem organizados, os estudantes sugeriram a confecção de cartazes, pois, assim, teriam a oportunidade de mostrar o trabalho realizado para os membros da escola.

Evidenciamos, assim, que ao valorizarmos o contexto e as diferenças existentes entre os estudantes, provocamos situações de ensino e aprendizagem que geraram a participação de todos, pois, conforme Hernández e Ventura (1998), Araújo (2014) e Schlünzen e Santos (2016) o trabalho com projetos permite a construção da aprendizagem de forma desafiadora, pois os 
conceitos podem ser vividos, formalizados e aprendidos de maneira globalizada, relacionando-os ao contexto e a realidade dos estudantes.

Diante das ações desenvolvidas, destacamos que os estudantes tiveram acesso a diferentes tipos de textos proporcionando, assim, atividades de leitura e interpretação, a partir da escrita e incentivo ao diálogo e as diferentes formas de expressão. Além disso, os estudantes tiveram a oportunidade de realizar uma pesquisa de dados, organizar os dados coletados e sistematizar os principais aspectos, a partir do problema que envolveu o projeto.

\section{DISCUSSÃO}

De acordo com Santos (2007) o trabalho com projetos não se relaciona com atividades desconexas e sem objetivos. As atividades surgem das necessidades do grupo para a construção de objetivos em comum. Desse modo, a partir dos resultados expostos, percebemos que o planejamento que envolveu a temática escolhida pelos estudantes proporcionou o desenvolvimento de atividades em que todos se sentiram ativos e pertencentes do ambiente escolar.

Conforme Puig e Martín (1998) apud Santos (2007), a construção de projetos a partir de temas proporciona uma educação em valores, uma vez que os estudantes são orientados para o desenvolvimento de atividades que legitimam a construção de uma consciência moral e ética. Além disso, proporciona a busca por respostas a problemas da sociedade, a busca pela união entre escola e vivência e a incorporação de temas aliados a problemas sociais.

\section{CONCLUSÃO}

A partir da descrição dos dados, resultados e análises evidenciamos que o trabalho com projetos possibilitou que os estudantes atuassem na sua aprendizagem, a partir do desenvolvimento de atividades que valorizaram o contexto educacional e social em que estavam inseridos. Além disso, as práticas vivenciadas proporcionaram a construção da consciência dos estudantes em relação à temática do projeto, pois eles tiveram a oportunidade de compreender e refletir sobre a problemática investigada.

Ao desenvolvermos práticas de ensino e aprendizagem mediadas pelo trabalho com projetos, compreendemos que a reinvenção do modelo educativo perpassa pela mudança de atitude, crenças e valores diante da constituição de uma escola inclusiva. Para isso, há a necessidade de se redefinir e de se colocar em ação novas práticas pedagógicas que favoreçam todos os estudantes, como preconiza Mantoan (2008).

Para que as estratégias de ensino e aprendizagem se reconfigurem, devemos valorizar os conhecimentos dos estudantes, as diferenças que os norteiam e as habilidades que possuem, para que, assim possamos agir na remoção de barreiras que impeçam a sua aprendizagem e desenvolvimento.

Diante desses preceitos, evidenciamos que o trabalho com projetos se configura como uma estratégia que possibilita a constituição de escolas inclusivas, pois considera as necessidades e as experiências dos estudantes, a partir da efetivação de práticas que proporcionam o desenvolvimento dos educandos em sua totalidade.

\section{REFERÊNCIAS}

ALMEIDA, M. E. B. Educação, projetos, tecnologia e conhecimento. São Paulo: PROEM, 2011.

ARAÚJO, U. F. Temas transversais, pedagogia de projetos e mudanças na educação. São Paulo: Summus, 2014. 
BOGDAN, R.; BIKLEN, S. Investigação qualitativa em educação: uma introdução à teoria e aos métodos. Porto: Porto editora, 1994.

FREIRE, P. Pedagogia do oprimido. 54 ed. Rio de Janeiro: Paz e terra, 2013.

HERNÁNDEZ, F; VENTURA, M. A organização do currículo por projetos de trabalho: o conhecimento é um caleidoscópio. 5 ed. Porto Alegre: Artmed, 1998.

LUDKE, M; ANDRÉ, M. E. D. A. Pesquisa em Educação: Abordagens Qualitativas. São Paulo: E.P.U, 1995.

MANTOAN, M. T. E. O desafio das diferenças nas escolas. Petrópolis: Editora Vozes, 2008.

SANTOS, Danielle Aparecida do Nascimento dos. A formação de professores de uma escola da rede pública estadual em serviço para o trabalho com projetos utilizando as tecnologias de informação e comunicação. 2006. 181 f. Dissertação (mestrado) - Universidade Estadual Paulista, Faculdade de Ciências e Tecnologia, 2006. Disponível em: <http://hdl.handle.net/11449/92326>.

SCHLÜNZEN, E. T. M.; SANTOS, D. A. N. Práticas pedagógicas do professor: abordagem Construcionista, Contextualizada e Significativa para uma educação inclusiva. Curitiba: Editora Appris, 2016.

SCHLÜNZEN, E. T. M. Abordagem Construcionista, Contextualizada e Significativa: formação, extensão e pesquisa em uma perspectiva inclusiva. 2015. 200f. Tese (Livre Docência). Universidade Estadual Paulista, Faculdade de Ciências e Tecnologia, Presidente Prudente/São Paulo. 